Editor's Note: In 2003, the Society for Neuroscience initiated the Science Educator Award to recognize an outstanding neuroscientist who has made significant contributions to the education of the public. For a description of the award, see http://www. sfn.org/sea. The Journal asked the 2009 winner, Janet M. Dubinsky, to give us her views on the importance of teaching teachers of kindergarten through 12th grade students about neuroscience.

\title{
Neuroscience Education for Prekindergarten-12 Teachers
}

\author{
Janet M. Dubinsky \\ Department of Neuroscience, University of Minnesota, Minneapolis, Minnesota 55455
}

A debate rages concerning the ability of neuroscience to inform prekindergarten-12 teaching practice (Hirsh-Pasek and Bruer, 2007; Varma et al., 2008). Some educators charged with training future teachers argue that the mechanistic issues that concern neuroscientists are too far removed from the classroom context to be able to effectively inform practice (Hirsh-Pasek and Bruer, 2007). At the far end of our field, neuroscientists attempt to apply the techniques of cognitive neuroscience to educationally relevant issues. Understanding the physiological processes mediating dyslexia or attention-deficit hyperactivity disorder has the potential to lead to biomarkers for diagnosis and strategies for successful early interventions (Fischer, 2009; Goswami, 2009). Studies of the cognitive capacities of infants and toddlers are leading to strategies for incorporating innate lexical and mathemati-

\footnotetext{
Received May 6, 2010; accepted May 11, 2010.

The BrainU program is currently funded by National Center for Research Resources (NCRR) Science Education Partnership Award (SEPA) R25RR025999 and National Institute on Drug Abuse Science Education Drug Abuse Partnership Award R25DA02395. Previous support for the BrainU program was provided by NCRR SEPA R25RR017315, Howard Hughes Medical Institute Pre-College Education Program for Biomedical Research Institutions Grant 72500-522006, Minnesota Department of Higher Education Eisenhower Grants A17496 and A32422, the University of Minnesota Medical School, and the University of Minnesota Academic Health Center. The success of the BrainU program is attributable to the energetic efforts of dedicated program staff, students, and faculty at the University of Minnesota and the Science Museum of Minnesota. The data in Figure 1 was collected by Dr. Michael Michlin as part of the program evaluation. The author gratefully acknowledges the thoughtful editorial assistance of Drs. Sashank Varma, William Cameron, and Gillian Roehrig, who critiqued drafts of this manuscript.

Correspondence should be addressed to Dr. Janet M. Dubinsky, Department of Neuroscience, University of Minnesota, 6-145 Jackson Hall, 321 Church Street SE, Minneapolis, MN 55455. E-mail: dubin001@umn.edu. DOI:10.1523/JNEUROSCI.2322-10.2010

Copyright $\odot 2010$ the authors $\quad 0270-6474 / 10 / 308057-04 \$ 15.00 / 0$
}

cal abilities into educational progressions (Meltzoff et al., 2009; Gilmore et al., 2010). Psychologists view neuroscience research as providing the physiological justification for the behavioral interventions they have long studied (Diamond and Amso, 2008). Businessmen view neuroscience as an exploitable body of information that can be used to successfully market educational products and services (e.g., Jensen Learning, Brain Gym). Teachers view neuroscience as a complicated body of knowledge that may explain what goes on in their students' heads (Brandt, 1999). Teachers feel that they need to understand both. However, the majority of neuroscientists are unaware of all of these issues.

In this essay, I will argue that neuroscientists as a community should address the issue of how neuroscience informs education by actively teaching neuroscience to teachers. We should move beyond occasional lectures to mass audiences and develop neuroscience courses for teachers that convey the basic principles of our field. I describe one such course, BrainU, and present data documenting how it changes teachers' knowledge of neuroscience and, critically, the quality of their science instruction.

Since teachers perceive that they need to know neuroscience, they form a natural audience for our teaching efforts. Teachers perceive they need to know how the brain works to become better professionals. Designing and delivering an interactive surveylevel course on nervous system function would empower teachers to similarly share this new knowledge with their own students. Both teachers-in-training and those returning for master's degrees could be targeted. Many teachers seek summer profes- sional development courses on in-depth topics relevant to their profession, providing opportunities for creative scheduling. Courses designed for a teacher audience would provide an additional source of tuition to departments beyond students in the health professions. Such efforts align with teaching expectations for academic faculty. A course designed with teachers' needs in mind could be evaluated and improved in an iterative, purposeful, and scholarly manner.

Teachers want to know how the nervous system works to understand the learning processes they try to stimulate in their students. Teachers engaged in guiding learners' intellectual development need to consider age-appropriate practices informed by our understanding of nervous system growth. Their demand to understand neuroscience has generated an explosion of conferences, educational products, and training opportunities that claim to be based on neuroscience. Commercial educational programs are marketed as based on brain research. While commercialization does disseminate ideas widely, the accuracy and fidelity of the information transfer also varies. Entrepreneurs have taken advantage of this market demand and have developed training sessions and product lines that often only really address classroom management techniques. At best these enterprises deliver lecture series on neuroscience topics that may impact or intersect with education (Learning and the Brain Society, 2010). At the worst, the products distort the neuroscience content or promote unsupported educational ideas (Cohen and Goldsmith, 2000).

To more directly address a teacher audience, neuroscientists need to provide 
training specifically in neuroscience topics related to education. This could take the form of large symposiums composed of a series of lectures on neuroscience topics (Learning and the Brain Society, 2010). Such gatherings are efficient uses of scientists' time, in that we are not obligated to do more than lecture to a large audience. This approach spreads general knowledge but fails to answer individual teachers' questions, to model specific strategies that can be used in the classroom, or to provide teachers with practice in applying this new knowledge. Best teaching practices involve more than just lecturing. Designing and delivering an interactive introductory course for a teaching audience provides an opportunity to use our experience with the scientific process to provide teachers with ways to explore nervous system function with their students. Integrating experimentation and hands-on activities into such a course can provide teachers with curriculum they can take into their own classrooms, assuring effective translation to their kindergarten (K)-12 audiences. Since teachers are apt to teach in the same manner in which they themselves learned the material, combining neuroscience content with educational practices informed by this knowledge will translate both concepts and technique in meaningful ways. Moreover, using open-ended classroombased investigations provides real experience in doing science to $\mathrm{K}-12$ students, a goal of many national science, technology, engineering, and mathematics education initiatives.

Tailoring a message specifically for teachers requires an approach that emphasizes the big ideas in neuroscience. The Neuroscience Core Concepts (Society for Neuroscience, 2008), developed by the Society for Neuroscience, begin to distill the take-home messages of our field for lay audiences. Teaching neuroscience to future educators provides an opportunity to examine what aspects of the field are most applicable to their profession. Teaching the detailed ionic basis of the action potential is not necessary. Understanding synaptic plasticity is. Our knowledge of synaptic plasticity provides teachers with hope that learning can occur in everyone. Understanding that all their students have the capacity to change their own brains may alter teachers' perceptions of student potential, enabling guidance, and may reinforce the student-centered views of teaching. Understanding that they are in charge of changing their own brains motivates middle school

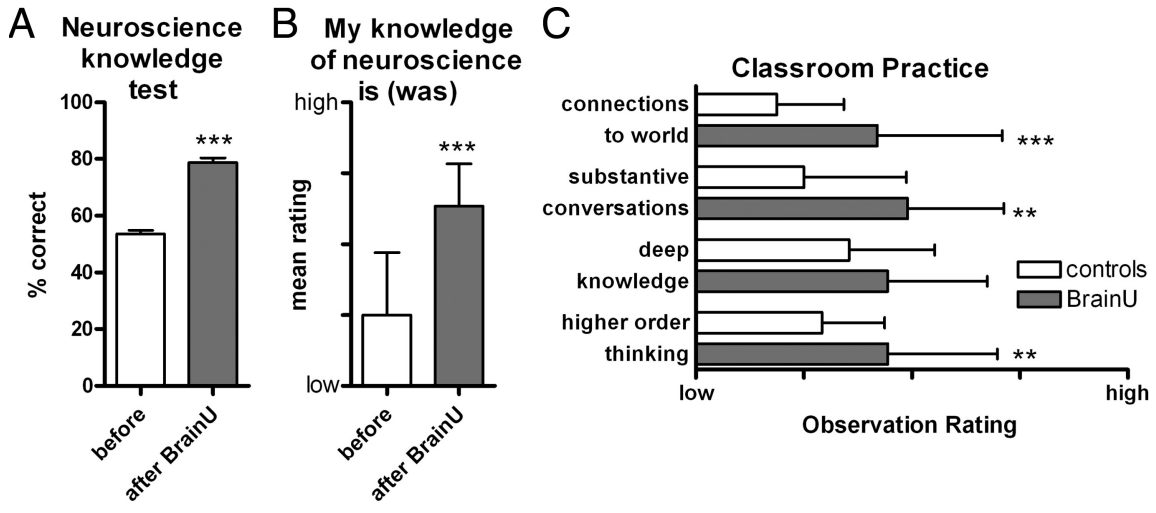

Figure 1. Changesinteacherneuroscienceknowledge $(\boldsymbol{A})$, confidence in that knowledge $(\boldsymbol{B})$, and pedagogical practices $(\boldsymbol{C})$ as a result of attending a single summer 2 week introductory BrainU workshop. $A$, Teacher content knowledge was assessed using an 11-question multiple-choice test given at the beginning and end of a BrainU workshop. Bars represent mean \pm SEM for $n=5$ separate workshops. $B$, Teachers rated their confidence in their neuroscience knowledge in surveys completed before and after attending BrainU. Bars represent mean \pm SD for $n=61$ teacher surveys at each time point. C, Science lessons in BrainU and control teachers' classrooms were observed by trained evaluators using Newmann's Standards of Authentic Instruction (Newmann et al., 1995). The Standards addressed characteristics observed in student thinking and classroom interactions. Higher-order thinking in which students combined facts and ideas to synthesize, generalize, explain, hypothesize, or arrive at a conclusion was distinguished from lower-order thinking involving repetitive receiving or reciting of factual information, rules, and algorithms. Depth of knowledge was assessed as the degree to which instruction and students' reasoning addressed the central ideas with enough thoroughness to explore connections and relationships and to produce relatively complex understandings and explanations. Substantive conversations tracked extended (at least 3 consecutive) conversational interchanges among students and the teacher about subject matter in a way that built an improved and shared understanding of ideas or topics. Connections to the world measured students' involvement and ability to connect substantive knowledge to public problems or personal experiences. Bars represent mean \pm SD for $n=46$ BrainU and $n=12$ control classrooms. ${ }^{*},{ }^{* *}$, and ${ }^{* * *}$ represent $p \leq 0.05,0.01$, and 0.001 , respectively, in two-tailed $t$ tests

students to apply themselves in school and may change their own educational trajectory (Blackwell et al., 2007). Embracing the idea that growing new synapses turns on genes as they learn provides students with hope that their efforts can lead to success (Blackwell et al., 2007). Understanding that the salience of an event determines its ability to be remembered (Fine and Minnery, 2009) may motivate teachers to actively engage learners to create that salience. In addition, neuroscience has made significant progress toward understanding specific mechanisms important to educators: dyslexia, sensitive periods, and adolescent brain development. This progress should also impact educational approaches (Petitto and Dunbar, 2004; Howard-Jones, 2007; Katzir, 2009). From the importance of sleep for memory consolidation (Van Der Werf et al., 2009; Vecsey et al., 2009) to the development of inhibitory control circuits (i.e., self restraint) during the adolescent years (Davidson et al., 2006; Geier and Luna, 2009), neuroscience touches on numerous issues that affect teaching: learning, mimicry, stress, social interactions, and self image (Kim et al., 2006).

BrainU is an example of an introductory neuroscience course tailored for teachers' needs (MacNabb et al., 2000). BrainU has been supported by a series of educational grants (see acknowledgments) to determine whether teachers could learn neuroscience and, critically, whether combining neuroscience with inquiry-based pedagogy can effectively change teachers' practice. The answer to both questions has been yes (MacNabb et al., 2006; Wakefield et al., 2008). BrainU delivered basic neuroscience knowledge using an experiential approach to learning about the nervous system. Teachers learned through observation, experimentation, hands-on activity, and discussions designed to be used in their middle school classrooms. Lectures accounted for $<20 \%$ of the workshop time. Teachers learned neuroscience in the manner they were expected to teach it to their students. In addition, by engaging in investigations designed for classroom use, teachers became sufficiently familiar with experimental processes that the inertial barrier to introducing experimentation into the classroom was lowered. Throughout this program, University of Minnesota neuroscientists partnered with pedagogy experts, first from the Science $\mathrm{Mu}$ seum of Minnesota and currently with educator colleagues from the University of Minnesota College of Education and Human Development.

Teachers who attended a 2 week, summer BrainU professional development workshop increased their knowledge of 
neuroscience and reported increasing their confidence in that knowledge (Fig. $1 A, B)$. Observations of their classrooms determined that the cognitive engagement among students and teachers also improved (Fig. 1C). Students maintained an interest in the brain activities, reported an increased interest in science, and favorably remembered the brain unit at the end of the school year (MacNabb et al., 2006). Thus, effectively taught neuroscience motivated teachers to improve their pedagogy and students to become engaged in science (MacNabb et al., 2006; Wakefield et al., 2008). Originally aimed at middle school audiences, BrainU was attended by teachers from all K-12 levels, including elementary, English and gym teachers as well as math and science teachers. The program is currently being expanded to address a high school audience, where more sophisticated concepts of nervous system control of homeostasis can be addressed and student performance assessed.

BrainU never directly dictated how neuroscience could inform teaching practice. At the end of each workshop day, teachers discussed or wrote in their journals about how the day's content and activities applied to their profession. Selected peer-reviewed articles from both the cognitive neuroscience and pedagogy literature were read and debated, building critical thinking skills. Teachers made their own connections regarding how neuroscience knowledge applied to their classrooms. Coming to these conclusions on their own may have strengthened the teachers' resolve to implement both the neuroscience content and the inquiry-based pedagogy.

The success of the BrainU program suggests that comparable courses may be equally welcomed in other universities and communities. Obtaining grant support for such endeavors should not be considered a prerequisite. Rather, forging the intrainstitutional partnerships between neuroscientists and teacher educators in schools of education should become the priority. Shortcutting directly to development of neuroscience courses for teacher audiences should be the local goal. BrainU syllabi, lessons, objectives, and classroom materials are all available online at www.brainu.org. Partner with teacher educators to craft the scientific messages in language and context appropriate for a teaching audience. Developing teaching collaborations with educators may result in finding common ground for research collaborations as well. If implemented successfully at many universities, neuroscience courses for teachers will become a requisite part of teacher preparation curricula. Teachers will begin paying tuition for the University of Minnesota BrainU course in the summer of 2010.

Training teachers in neuroscience could be considered an alternative form of public engagement. Middle and high school teachers, especially those who teach science, become an attractive audience for such dissemination. A secondary teacher may work with 150-200 students a year. Educating 25 teachers can leverage a scientist's time to reach up to 5000 students annually. Elementary and early education teachers see fewer students on an annual basis but require an even greater depth of knowledge regarding the developmental progression of younger students. Given the explosion of knowledge in the realm of early childhood cognitive development and the importance of early emotional and language learning for future success, neuroscience training for day care workers and preschool teachers becomes an even greater imperative with perhaps a greater societal impact. Educational futurists predict that parent-teacher conferences will one day become discussions interpreting brain imaging or gene-chip data (Gardner, 2009). In these scenarios, teachers would of necessity have to understand brain function at more than a superficial level. As neuroscientists, we are responsible for training teachers to understand and to be able to judge whether such information should inform classroom practice and performance.

Bridging the gap between neuroscience and education is a continuing process between uncovering cellular and systemsbased mechanisms and developing effective actions and practices in the classroom. As neuroscientists, we are not expected to be experts in translating new scientific knowledge into educational practice. But sharing our growing knowledge of brain structure and function with educators, especially as it applies to developing cognitive functions, is an important part of the process toward filling the gap. Scientists are responsible for communicating accurately the new knowledge of our respective fields to those charged with applying it. Thus we are obligated to and should actively engage in sharing this new knowledge with teachers. We need to go beyond the multifaceted approaches of Brain Awareness Week to actively focus our efforts on informing teachers at all levels, from early education to high school and ourselves at the collegiate level, of our growing understanding of learning, brain plasticity, and cognitive conceptualization.

\section{References}

Blackwell LS, Trzesniewski KH, Dweck CS (2007) Implicit theories of intelligence predict achievement across an adolescent transition: a longitudinal study and an intervention. Child Development 78:246-263.

Brandt R (1999) Educators need to know about the human brain. Phi Delta Kappan 81:235.

Cohen I, Goldsmith M (2000) Hands on: how to use Brain $\mathrm{Gym}^{\circledR}$ in the classroom. Sea Point, South Africa: Hands On Books.

Davidson MC, Amso D, Anderson LC, Diamond A (2006) Development of cognitive control and executive functions from 4 to 13 years: evidence from manipulations of memory, inhibition, and task switching. Neuropsychologia 44:2037-2078.

Diamond A, Amso D (2008) Contributions of neuroscience to our understanding of cognitive development. Curr Dir Psychol Sci 17: 136-141.

Fine MS, Minnery BS (2009) Visual salience affects performance in a working memory task. J Neurosci 29:8016-8021.

Fischer KW (2009) Mind, brain, and education: building a scientific groundwork for learning and teaching. Mind Brain Educ 3:3-16.

Gardner H (2009) An education grounded in biology: interdisciplinary and ethical considerations. Mind Brain Educ 3:68-73.

Geier C, Luna B (2009) The maturation of incentive processing and cognitive control. Pharmacol Biochem Behav 93:212-221.

Gilmore CK, McCarthy SE, Spelke ES (2010) Non-symbolic arithmetic abilities and mathematics achievement in the first year of formal schooling. Cognition 115:394-406.

Goswami U (2009) Mind, brain, and literacy: biomarkers as usable knowledge for education. Mind Brain Educ 3:176-184.

Hirsh-Pasek K, Bruer JT (2007) The brain/education barrier. Science 317:1293.

Howard-Jones PA (2007) Neuroscience and education: issues and opportunities. Retrieved September 25, 2009 from http://www. tlrp.org/pub/documents/Neuroscience $\%$ 20Commentary\%20FINAL.pdf.

Katzir T (2009) How research in the cognitive neuroscience sheds lights on subtypes of children with dyslexia: implications for teachers. Cortex 45:558-559.

Kim JJ, Song EY, Kosten TA (2006) Stress effects in the hippocampus: synaptic plasticity and memory. Stress 9:1-11.

Learning and the Brain Society (2010) Learning and the brain. Retrieved May 2, 2010 from http://www.edupr.com/.

MacNabb C, Schmidt L, Minor S, Roehrig GH, DubinskyJM (2000) BrainU: the neuroscience teacher institute. Retrieved January 1, 2010 from http://brainu.org/brainu-neuroscience-teacherinstitute.

MacNabb C, Schmitt L, Michlin M, Harris I, Thomas L, Chittendon D, Ebner TJ, Dubinsky JM (2006) Neuroscience in middle schools: a professional development and resource program that models inquiry-based strategies and engages teachers in classroom implementation. CBE Life Sci Educ 5: 144-157. 
Meltzoff AN, Kuhl PK, Movellan J, Sejnowski TJ (2009) Foundations for a new science of learning. Science 325:284-288.

Newmann FM, Secada WG, Wehlage GG (1995) A guide to authentic instruction and assessments: vision, standards and scoring. Madison, WI: Wisconsin Center for Education Research.

Petitto LA, Dunbar K (2004) New findings from educational neuroscience on bilingual brains, scientific brains, and the educated mind. In: Building usable knowledge in mind, brain, and education (Fischer $\mathrm{K}$,
Katzir T, eds). Cambridge UK: Cambridge UP.

Society for Neuroscience (2008) Neuroscience core concepts. The essential principles of neuroscience. Retrieved January 1, 2010 from http://www. sfn.org/index.aspx?pagename $=$ core_concepts.

Van Der Werf YD, Van Der Helm E, Schoonheim MM, Ridderikhoff A, Van Someren EJ (2009) Learning by observation requires an early sleep window. Proc Natl Acad Sci U S A 106:18926-18930.

Varma S, McCandliss BD, Schwartz DL (2008)
Scientific and pragmatic challenges for bridging education and neuroscience. Educational Researcher 37:140-152.

Vecsey CG, Baillie GS, Jaganath D, Havekes R, Daniels A, Wimmer M, Huang T, Brown KM, Li XY, Descalzi G, Kim SS, Chen T, Shang YZ, Zhuo M, Houslay MD, Abel T (2009) Sleep deprivation impairs cAMP signalling in the hippocampus. Nature 461:1122-1125.

Wakefield B, Baker D, Waskow CEG, Dubinsky JM (2008) Benefits to teachers of multiple year participation in BrainU. Soc Neurosci Abstr 34:222.20/UU8. 